\title{
obituaries
}

\section{Clair Gurney}

\section{Formerly Consultant}

Psychiatrist, St Nicholas

Hospital, Newcastle-upon-

Tyne

Clair Gurney was born in Whitley Bay in 1933, qualified in medicine at the University of Edinburgh and then returned to her roots in the north-east of England for her house appointments and for the rest of her career. She began in psychiatry as a junior hospital medical officer at St Nicholas Hospital in Newcastle-upon-Tyne until invited by Professor (later Sir) Martin Roth to join the research team he had started to assemble. The group was later funded by the Medical Research Council and Clair remained there as senior research associate for 16 years, a length of tenure which conveyed the high regard in which she was held by Professor Roth and his colleagues.

Clair was meticulous, thorough and reliable in her research projects. Her prime role was to obtain biographical, personality and clinical information from patients by personal interview using a structured pro forma and to record a detailed, descriptive history. The 1960s and 1970s were a time when junior research psychiatrists in Newcastle were given generous time and resources, as well as expert guidance and advice from Martin Roth and Roger Garside. In a study carried out with physicians, the data Clair

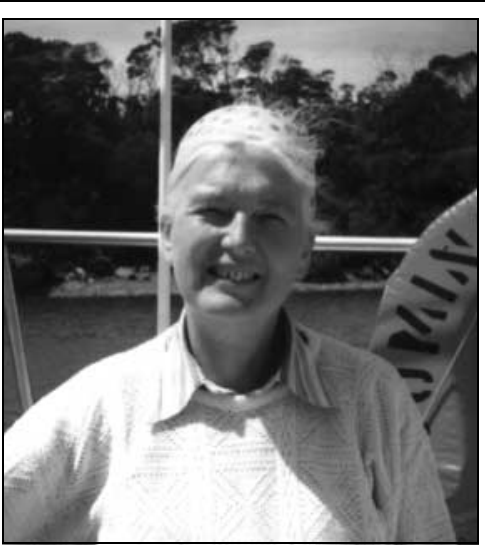

collected demonstrated that items from psychiatric observation added substantially to the information from physical symptoms and signs, and laboratory tests, in the differentiation of thyrotoxic from euthyroid patients with psychiatric disorder among a group of patients with suspected hyperthyroidism. The foundation of a larger investigation into the differentiation of anxiety states and depressive disorders again rested on the quality of information painstakingly elicited by Clair in the course of structured interview. Her sensitivity and empathy ensured whole-hearted cooperation from patients, which was much appreciated by her colleagues who interviewed the same patients at follow-up 4 years later.

Clair also acquired a thorough understanding of the application of multivariate statistical analyses which were emerging at that time and which enable systematic examination of the presence of symptom clusters, patient groupings, diagnostic separations and predictive indices within the field of affective disorders. In a session in this field held at the World Psychiatric Association meeting in Mexico City, Clair charmed the audience by delivering her opening remarks in fluent Spanish.

After her lengthy period in research Clair returned to St Nicholas Hospital as associate specialist, remaining there unti retirement in 1988, having repeatedly declined exhortations from her colleagues to apply for a permanent consultant post (although she eventually accepted an acting post), as she wished to have regular time to support her mother and sister.

Clair was a private person with a delightful sense of humour. Those who worked with her recall with affection her charm, modesty, thoughtfulness and generosity of spirit. In retirement she was able to devote more time to her life-long passion for birdwatching, often using the caravan she and her husband lan, a senior lecturer in theoretical physics, enjoyed on the Northumberland coast. Her other great pleasure was playing the piano. It is poignant that failing strength in her fingers was the first symptom of motor neurone disease which Clair herself diagnosed, and which ran a rapidly progressive course to the time of her death in June 2006.

Alan Kerr

doi: 10.1192/pb.bp.107.015750

\section{David Richard Kilvington Street}

\section{Formerly Medical}

\section{Superintendent, Rampton Hospital}

David Street graduated MB ChB in Leeds in 1943 and was a house physician at Leeds General Infirmary until 1944 when he moved to Pinderfields Emergency Hospital, Wakefield. Between 1944 and 1946 David was the clinical assistant of the neurological unit attached to Sheffield Royal Hospital. It was here that he became involved in general psychiatry and neurology. His National Service between 1945 and 1948 was spent in psychiatry at Carstairs Military Hospital and Northfield Neurosis Centre, Birmingham. Between 1948 and 1951 he was a registrar at Clifton Hospital in York. His move to the post of senior registrar took him to the

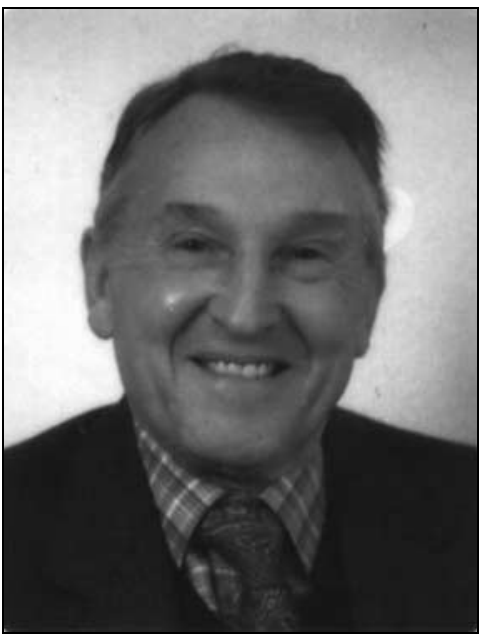

following year, at the age of 38 , he became Consultant Psychiatrist and Deputy Medical Superintendent at Rampton Hospital, Nottinghamshire. A few months later he was to become the Medical Superintendent, a position which he held with esteem until 1974. He moved in that year to Moss Side Hospital, Maghull, Liverpool and remained there until his retirement in 1980. Between 1960 and 1973 he was involved in much collaborative work on chromosome abnormalities and published several papers.

Dr Street was elected a founder member of the Royal College of Psychiatrists in 1971 and was elected to FRCPsych in 1989. He died on 7 June 2006, having been predeceased by his wife, Helen, in 2004. He leaves behind a daughter and two grandchildren.

\section{Elizabeth M. Cooke}

In 1957 he moved to Broadgate Hospital, Beverley, East Yorkshire. The

York Retreat but he returned to Clifton doi: 10.1192/pb.bp.107.015768 